\title{
Tool Wear And Cutting Forces When Machining Inconel 718 Under Cryogenic Conditions: Liquid Nitrogen and Carbon Dioxide
}

\author{
S. Chaabani ${ }^{1,2, a)}$, I. Rodriguez ${ }^{1}$, M. Cuesta ${ }^{1}$, Y. Ayed ${ }^{2}$, P.J. Arrazola ${ }^{1}$ and G. \\ Germain $^{2}$ \\ ${ }^{1}$ Faculty of Engineering, Mondragon Unibertsiatea, 20500 Mondragon, Spain. \\ ${ }^{2}$ Arts et Metiers, LAMPA, 2 boulevard du Ronceray, 49035 Angers, France. \\ ${ }^{a)}$ Corresponding author: schaabani@ mondragon.edu
}

\begin{abstract}
Nickel-based superalloys are widely exploited in turbojets components which are subjected to intense thermal and mechanical loadings during their operation. In fact, they exhibit excellent mechanical properties over a wide range of temperature and high corrosion and creep resistance. However, these materials induce several problems related to the shaping by machining due to essentially high heat resistance, high hardening tendency, high chemical affinity with tool material and low thermal conductivity leading to very high temperature in the cutting zone. In this context, assisted machining processes aim to improve the productivity of certain materials that are difficult to cut. Indeed, in order to keep the tool cold, it has been proposed to use cryogenic fluids (liquid nitrogen $\mathrm{LN}_{2}$ and carbon dioxide $\mathrm{CO}_{2}$ as coolant for effectively reducing temperatures since their vaporization temperatures are equal to $-196^{\circ} \mathrm{C}$ and $-75^{\circ} \mathrm{C}$ respectively. In this context, previous researches have focused on the study of the efficiency of this technique with respect to the machinability of several materials such as titanium alloys and nickel-based alloys. It has been shown that the tool life is improved when machining titanium alloys, unlike nickel-based alloys. For this reason, this paper is devoted to a comparison between two cryogenic fluids $\left(\mathrm{LN}_{2}\right.$ and $\left.\mathrm{CO}_{2}\right)$ with regard to their effects on tool life when machining Inconel 718 considering as a reference the conventional lubrication.
\end{abstract}

Keywords: Machining, Inconel 718, Cryogenic, Tool wear.

\section{INTRODUCTION}

Nickel superalloys reveal excellent mechanical properties at high temperature, high corrosion and creep resistance. Consequently, nickel based alloys are largely employed in the aeronautic applications. However, such alloys are difficult to cut materials due to many reasons such as the strain hardening while machining process [1]. In addition, these alloys present high chemical affinity with most of tool material leading to rapid wear of the tool by adhesion and diffusion mechanisms [2,3]. Moreover, the nickel based alloys exhibit very low thermal conductivity inducing high cutting temperature at the cutting zone $[4,5]$. For these reasons, to maintain the tool cold as possible and thus to decelerate tool wear evolution, it is relevant to use assisted machining process for instance, high pressure water jet $[6,7]$ as well as cryogenic machining process $[8,9]$. In addition, cryogenic process provides an ecological and safe alternative motivating to industrial applications. In this context, previous works have figured out the effect of cryogenic machining on tool wear when machining hard to cut materials either in the case of using liquid nitrogen $\mathrm{LN}_{2}$ or carbon dioxide $\mathrm{CO}_{2}$. Indeed, Ayed et al [10] have reported the effect of cryogenic cooling on tool wear, especially tool flank wear. Following the tests carried out during the machining of the Ti64 alloy, they have figured out that the evolution of the tool flank wear, is less important in the cryogenic conditions using the liquid nitrogen compared with dry and conventional cooling conditions. Indeed, under dry and conventional conditions, the tool life is lower than $2.5 \mathrm{~min}$ and $6 \mathrm{~min}$ respectively. In contrast, after $15 \mathrm{~min}$ of machining, the tool flank wear does not exceed $0.2 \mathrm{~mm}$ under cryogenic conditions when the liquid nitrogen was maintained at high flow rate and high pressure. They have explained this by the fact that the nitrogen jet contributes to lowering the cutting temperature and subsequently to control relatively the wear mechanisms [11]. 
Thereafter, Kaynak [12] has investigated the performance of Inconel 718 under cryogenic assistance machining by comparing it with dry and MQL machining conditions. Indeed, during the tests, he chose two nozzles to throw the liquid nitrogen at the cutting face and the flank of the tool. The results obtained indicate a good agreement with the results cited above with respect to the reduction in the tool flank wear by comparing the other machining modes namely dry and MQL machining conditions. In fact, the largest measure has been identified in the case of dry machining. However, the MQL approach provided values slightly close to those obtained in cryogenic machining up to $2.5 \mathrm{~min}$ and then the tool flank wear increases rapidly to show the same trend as the dry condition.

Recently, Iturbe et al [1] have conducted an extensive research to estimate the extent to which conventional lubrication could be replaced by cryogenic fluid $\left(\mathrm{LN}_{2}\right)$. To do this, they took over the same configurations exploited by Kaynak (the work material Inconel 718, the cutting parameters, the geometry of the tool). Indeed, the tests were carried out under two conditions namely conventional machining and machining associating MQL and cryogenic fluid. As a result, the findings revealed that the tool life presents a significant difference between conventional lubrication and cryogenic conditions. In the case of conventional machining, the life of the tool exceeds 20 min and shows a homogeneous evolution. However, in the other case (MQL + cryogenic), the evolution of the tool wear occurs quickly and the standard criterion of the life of the tool is reached for shorter times (less than $7 \mathrm{~min}$ ). This is likely due to the fact that the machined material Inconel 718 has a tendency to hardening excessively under the effect of cryogenic temperatures. Thereby, generating the degradation of the tool and consequently the reduction of its life.

Few researches have studied the effect of cryogenic machining using carbon dioxide $\mathrm{CO}_{2}$ as a cutting fluid performed on several workpiece materials for instance hardened steel, Ti64 and Inconel 718 [13, 14]. Indeed, it has been reported that cryogenic machining using the $\mathrm{CO}_{2}$ showed better performance in terms of tool life or cutting length in comparison with the $\mathrm{LN}_{2}$ cryogenic condition, dry and traditional lubrication. For instance, Jerold et al [15] have figured out the effect of cryogenic fluids $\left(\mathrm{LN}_{2}\right.$ and $\left.\mathrm{CO}_{2}\right)$ on tool wear considering as a reference the conventional lubrication. Subsequently, Bagherzadeh et al [16] have carried out an extensive study focusing on $\mathrm{CO}_{2}$ cryogenic cooling approach using different configurations. In fact, during the experiments, they have employed four cooling strategies consisting in: cooling the tool rake face using the $\mathrm{CO}_{2}$ cryogenic fluid, cooling the rake face using $\mathrm{CO}_{2}$ and the flank face using MQL, combining the $\mathrm{CO}_{2}$ fluid and the MQL to cool the tool rake face (CMQL) and using a modified nozzle to cool simultaneously rake and flank faces using the $\mathrm{CO}_{2}$ cutting fluid. The following table highlights a summary of the results obtained in the previous works carried out when machining several materials under cryogenic conditions focusing on the $\mathrm{CO}_{2}$ performance compared with dry, MQL or wet conditions (Table 1).

TABLE 1. Summary of the previous studies showing the effect of the $\mathrm{CO}_{2}$ performance compared to different cooling methods

\begin{tabular}{lllccc}
\hline Cooling conditions & Work Material & $\begin{array}{c}\text { Machining } \\
\text { operations }\end{array}$ & $\begin{array}{c}\text { Cutting speed } \\
(\mathrm{m} / \mathrm{min})\end{array}$ & $\begin{array}{c}\text { Tool wear } \\
\text { reduction } \\
\%\end{array}$ & $\begin{array}{c}\text { Cutting } \\
\text { length } \\
(\mathrm{m})\end{array}$ \\
\hline Wet-LN $-\mathrm{CO}_{2}[15]$ & AISI 1045 steel & Turning & 94 & $91^{\dagger}$ & \\
Wet-LN $_{2}-\mathrm{CO}_{2}[15]$ & AISI 1045 steel & Turning & 145 & $81.5^{\dagger}$ & \\
$\mathrm{MQL}^{\dagger} \mathrm{CO}_{2}[16]$ & Ti64 & Turning & 150 & - & $42.8^{*}$ \\
$\mathrm{MQL}^{*} \mathrm{CO}_{2}[16]$ & Inconel 718 & Turning & 100 & - & $37.4^{*}$ \\
\hline
\end{tabular}

* Cutting length obtained in $\mathrm{CO}_{2}$ cooling condition.

$\dagger$ Reduction of tool wear obtained in $\mathrm{CO}_{2}$ compared to wet condition.

So far, according to the review literature, there is no study that has focused on the comparison between the cryogenic fluids performance namely $\mathrm{LN}_{2}$ and $\mathrm{CO}_{2}$ when machining Inconel 718 using the same cutting parameters in order to identify the influence of each cryogenic fluid on Inconel 718 machinability.

This paper is dedicated to examine the effect of the latter cryogenic fluids on tool life when machining Inconel 718 considering as a reference the conventional lubrication. Therefore, the experimental methodology is detailed followed by a comparison between the cryogenic configurations performance and traditional lubrication in terms of tool life. Cutting forces are also included. 


\section{Experimental methodology}

\section{Experimental set-up}

Machining trials were carried out under conventional coolant and cryogenic cutting fluids using liquid nitrogen $\mathrm{LN}_{2}$ and carbon dioxide $\mathrm{CO}_{2}$. The trials were performed using the same test configuration on a horizontal turning CNC lathe Danumeric 2. Turning tests with the conventional lubrication were conducted cooling the cutting zone with the HOCUT 3380 fluid. As for the cryogenic tests using $\mathrm{LN}_{2}$ as a coolant, the cryogenic system is composed of the phase separator, the cryogenic control and the liquid nitrogen bottle mounted on the $\mathrm{CNC}$ lathe. $\mathrm{LN}_{2}$ spray was activated before beginning the machining process in order to achieve stable outlet condition. With respect to the $\mathrm{CO}_{2}$ system, it is composed of a bottle of $\mathrm{CO}_{2}$ maintained at high pressure equal to 57 bars at room temperature (Fig 1).

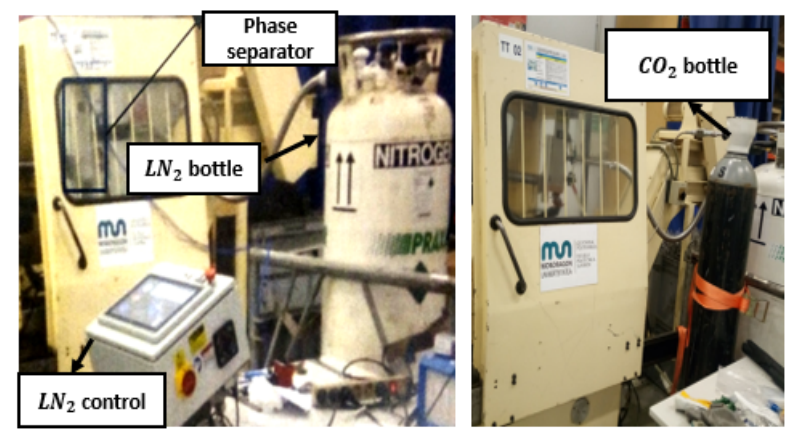

FIGURE 1. Experimental cryogenic systems: $\mathrm{LN}_{2}$ and $\mathrm{CO}_{2}$

\section{Experimental procedure}

Longitudinal turning experiments were conducted in finishing operations on forged Inconel 718 bar using the same cutting parameters and the same cutting tool as Iturbe [1], that are a cutting speed of $70 \mathrm{~m} / \mathrm{min}$, a feed per revolution of $0.2 \mathrm{~mm} / \mathrm{rev}$ and a depth of cut of $0.2 \mathrm{~mm}$. However, three cooling ways were employed: $\mathrm{LN}_{2}$ (the delivery position and the diameter of the nozzle have been changed compared to [1]), $\mathrm{CO}_{2}$ and conventional cooling. CVD coated carbide inserts from Mitsubishi supplier (DNMG 150612-MS US905) having a tool nose radius of $1.2 \mathrm{~mm}$ were exploited in the trials. Table 2 sets out the machining conditions:

TABLE 2. Working conditions

\begin{tabular}{lll}
\hline Workpiece & Geometry & Cylindrical bar \\
& Material & Inconel 718 \\
Cutting parameters & Cutting speed $(\mathrm{m} / \mathrm{min})$ & 70 \\
& Depth of cut $(\mathrm{mm})$ & 0.2 \\
\multirow{5}{*}{ Coolants } & Feed $(\mathrm{mm} / \mathrm{rev})$ & 0.2 \\
& Conventional & Hotcut \\
& Cryogenic & $\mathrm{LN}_{2}$ \\
& Cryogenic & $\mathrm{CO}_{2}$ \\
\hline
\end{tabular}

The experimental tests were conducted until reaching the target machining time (15 $\mathrm{min}$ ) or when the maximum tool life defined as $\mathrm{V}_{b \max }=0.3 \mathrm{~mm}$ was reached according to the standard 3685:1993.

Each experiment has been carried out two times using the same cutting tool edge under each cooling condition and the average values have been exploited for the analysis. Tool flank wear measurements have been recorded using a LEICA Z16 APO macroscope after each cutting test. Furthermore, the cutting forces were recorded using Kistler 9121 dynamometer. 


\section{Results and discussions}

\section{Tool wear}

Tool flank wear evolution was recorded during the longitudinal turning trials in all cooling strategies (conventional and cryogenic conditions). The experiments were stopped at a machining time of 15 minutes in wet condition even if the maximum flank wear did not exceed the criterion of $\mathrm{V}_{\text {bmax }}=0.3 \mathrm{~mm}$. Nevertheless, under cryogenic conditions, the experiments were stopped when the tool flank wear achieved the criterion value. As illustrated in Fig 2, results showed that the tool life in conventional condition is the longest duration achieved. Indeed, the tool flank wear does not exceed $0.12 \mathrm{~mm}$ after 15 minutes of machining in wet condition. Regard the $\mathrm{CO}_{2}$ cooling condition, the same tendency of tool wear evolution has been observed until reaching 12 min of machining. However, after 12 min, tool flank wear increases notably to exceed the criterion at $15 \mathrm{~min}$. As for $\mathrm{LN}_{2}$ cryogenic condition, this parameter increased rapidly from the first 2 minutes of machining leading to shorter tool life. Additionally, under $\mathrm{LN}_{2}$ cryogenic condition, the chipping of the cutting tool was drastically pronounced compared to the conventional lubrication. Furthermore, it should be noted that the tool wear evolution under both cryogenic conditions is quite repeatable at the beginning of the cutting process. However, a notable variability occurred at $11 \mathrm{~min}$ and 13 min respectively under $\mathrm{LN}_{2}$ and $\mathrm{CO}_{2}$ cooling approaches when the tool flank wear evolved significantly. Overall, under conventional coolant environment, a homogeneous tool flank wear evolution was observed even after longer machining times showing a good repeatability. Nevertheless, in $\mathrm{LN}_{2}$ cryogenic machining condition, wear peaks were recorded from the beginning of the turning process, revealing that the cutting process is not performed homogeneously whereas this parameter reveals a steady and slow evolution under $\mathrm{CO}_{2}$ cryogenic condition except the last minutes of machining as shown in Fig 3.

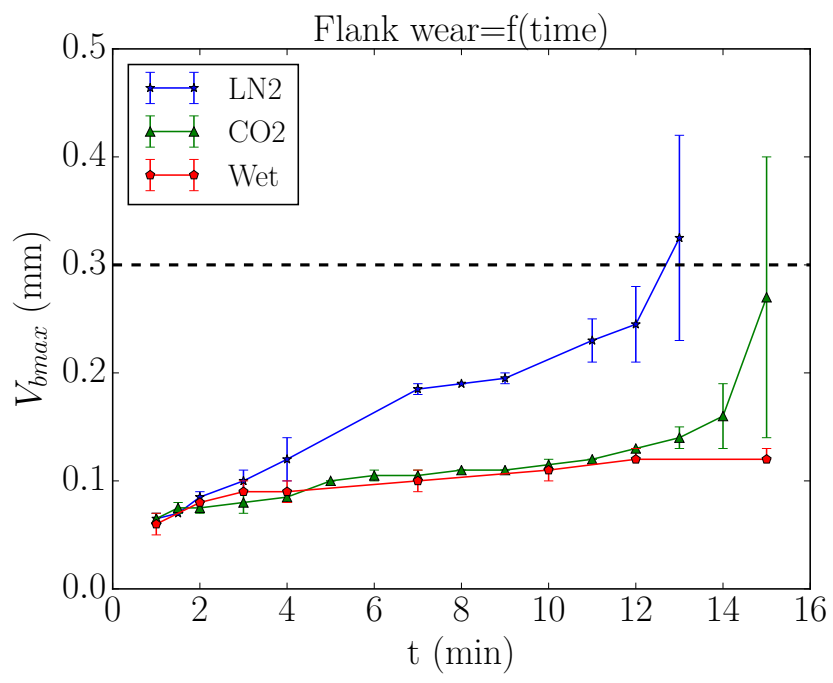

FIGURE 2. Tool flank wear evolution in different cooling conditions: Wet, $\mathrm{LN}_{2}$ and $\mathrm{CO}_{2}$.

a)

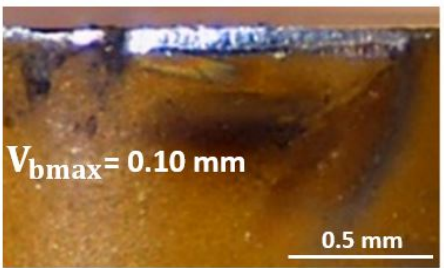

b)

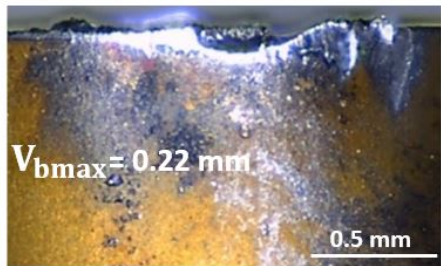

c)

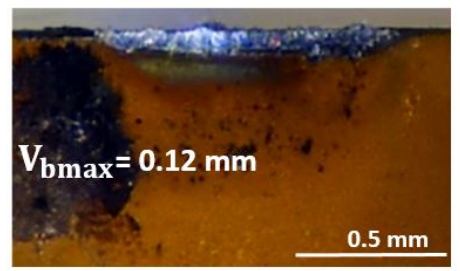

FIGURE 3. Comparison of tool flank wear evolution in different cooling conditions: a) Wet, b) $\mathrm{LN}_{2}$ and c) $\mathrm{CO}_{2}$ after 10 min of machining. 


\section{Cutting forces}

The cutting forces are crucial factors that indicate the power consumption in the machining process. Actually, the cutting forces components are strongly dependent on several parameters for instance the workpiece properties, the cutting tool material and geometry as well as the coolant strategy. In this work, one is interested to figure out the tendency of cutting forces components when machining Inconel 718 under wet and cryogenic conditions $\left(\mathrm{LN}_{2}\right.$ and $\mathrm{CO}_{2}$ ) that reveal the state of tool wear. Indeed, the cutting, the feed and the passive forces are significantly higher under cryogenic cooling environments than in the case of conventional lubrication (Fig 4 and Fig 5).
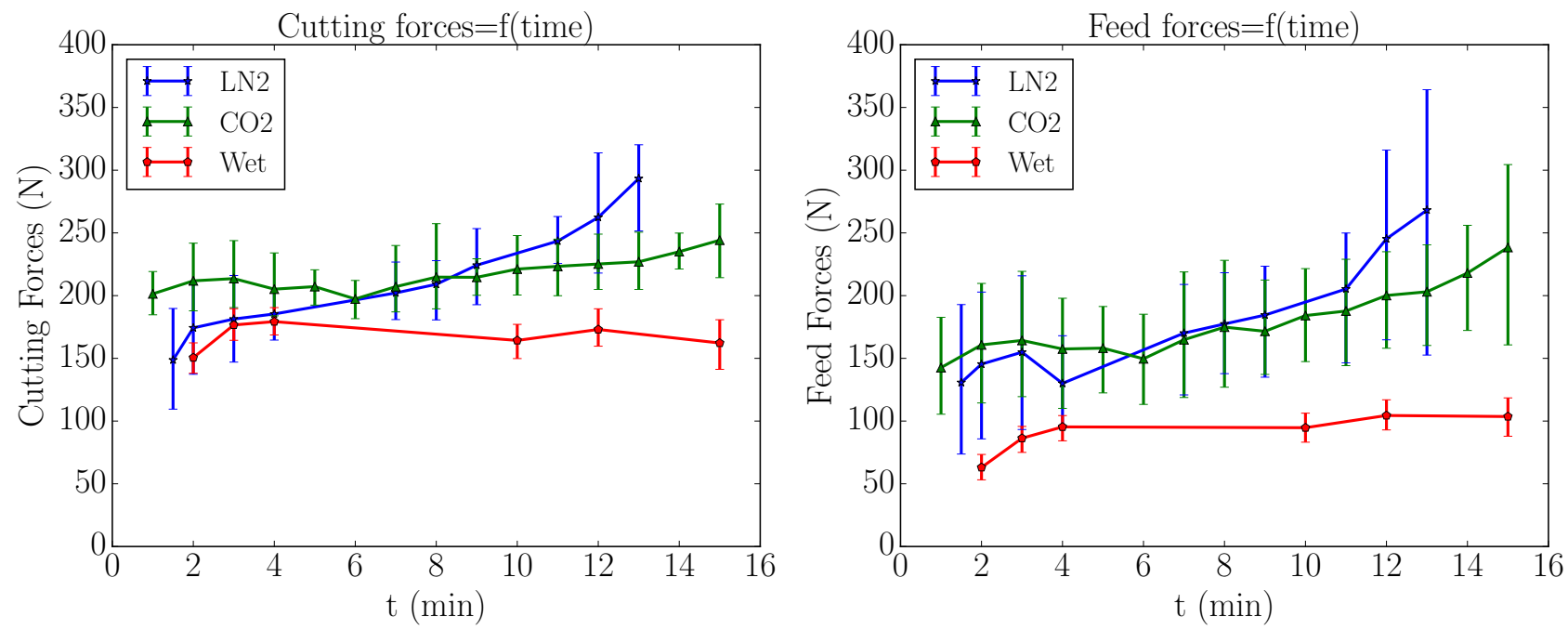

FIGURE 4. Comparison between cutting forces components evolution in different cooling conditions: $\mathrm{Wet}_{2} \mathrm{LN}_{2}$ and $\mathrm{CO}_{2}$ : Cutting forces (left) and Feed forces (right).

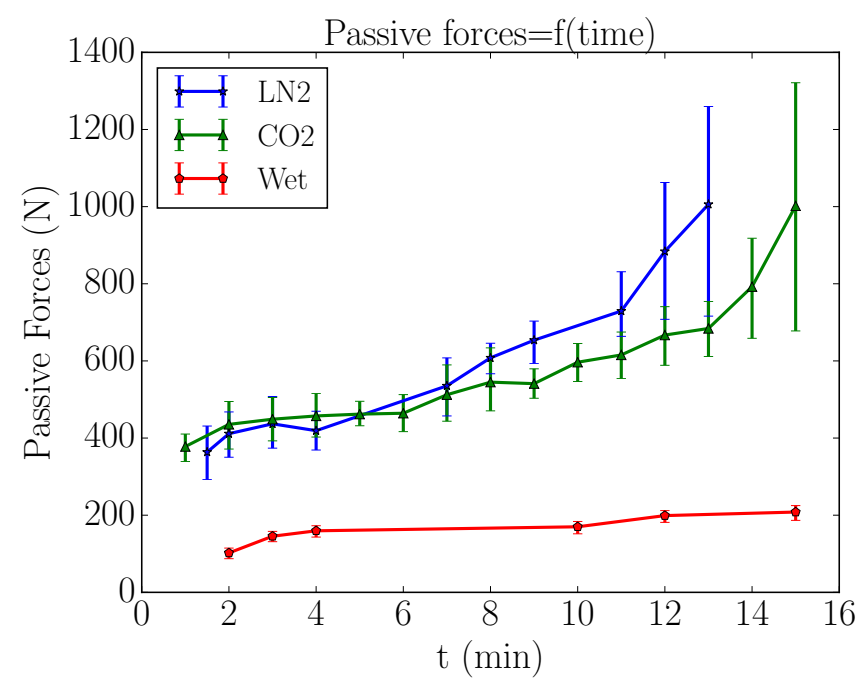

FIGURE 5. Comparison between passive forces evolution in different cooling conditions: Wet, $\mathrm{LN}_{2}$ and $\mathrm{CO}_{2}$.

Actually, the cryogenic fluids namely $\mathrm{LN}_{2}$ and $\mathrm{CO}_{2}$ exhibit very low temperature during the machining tests inducing likely higher flow stresses of the workpiece material even before cutting. Probably, this is could be because of a notable cooling effect of the cryogenic fluids preventing the material softening. Consequently, the cutting forces components increase drastically. Focusing on the tendency of the three components of the cutting forces obtained 
in conventional condition that showed lower values when machining Inconel 718 in comparison with $\mathrm{LN}_{2}$ and $\mathrm{CO}_{2}$ cryogenic fluids. In fact, the maximum value of cutting forces that has been recorded in conventional condition is 180 $\mathrm{N}$ while in $\mathrm{LN}_{2}$ and $\mathrm{CO}_{2}$ cooling conditions, this parameter has exceeded $300 \mathrm{~N}$ and $250 \mathrm{~N}$ respectively. Moreover, the feed forces reveal the same tendency where the maximum values are obtained under $\mathrm{LN}_{2}$ cryogenic conditions. In contrast, the passive forces showed the highest values measured in all cooling approaches compared to the cutting and feed forces. Results revealed huge values obtained in both cryogenic conditions compared to conventional lubrication. Additionally, it should be noted the strong correlation between the tendency of passive forces and the evolution of tool flank wear. Effectively, one can figure out the trends of the passive forces with tool flank wear state at different machining times under all cooling conditions namely the conventional and the cryogenic cutting fluids. As obviously illustrated in all figures, as the machining time increases, the tool flank wear increased as well. Thereby, passive forces increased relatively to the coolant condition. In particular, passive forces evolution is steady and slow in wet condition unlike the cryogenic conditions where the passive forces rise quite notably. This phenomenon is more pronounced in $\mathrm{LN}_{2}$ cooling environment than in $\mathrm{CO}_{2}$ condition. This fact may be due to the rapid tool flank wear evolution in $\mathrm{LN}_{2}$ cryogenic condition indicating that the passive forces are the most sensitive to tool flank wear.

\section{Conclusion}

In this paper, a literature review was reported concerning the study of the poor machinability of nickel-based superalloy Inconel 718. Then, the machining performance of the work material was identified by mentioning the major research that have focused on the cryogenic cooling effect on tool wear when machining Inconel 718.

Subsequently, machining trials using three different cooling conditions namely conventional and $\mathrm{LN}_{2}$ and $\mathrm{CO}_{2}$ cryogenic conditions have been presented. The experimental results showed the good performance during machining of conventional coolant in terms of tool life reaching 15 min knowing that the flank wear does not achieve the criterion. In contrast, the $\mathrm{LN}_{2}$ condition indicates shorter tool life revealing a rapid and non homogeneous tool flank wear. With respect to the $\mathrm{CO}_{2}$ cooling condition, the tool flank wear showed slight difference compared to the conventional lubrication performance only at longer machining time.

Additionally, the cutting forces components showed higher value in the case of cryogenic environments than in conventional condition due to the significant cooling effect.

Finally, for enhancement purposes, one is extremely interested in understanding the main tool wear mechanisms under the whole cooling strategies. For this reason, extensive analysis will be conducted using SEM technique as well as the surface integrity investigation (microstructure damage and residual stresses).

\section{REFERENCES}

[1] A. Iturbe, E. Hormaetxe, A. Garay, and P. Arrazola, Procedia CIRP 45, 67-70 (2016).

[2] G. R. Thellaputta, P. S. Chandra, and C. Rao, Materials Today: Proceedings 4, 3712 - 3721 (2017).

[3] M. Imran, P. T. Mativenga, A. Gholinia, and P. J. Withers, International Journal of Machine Tools and Manufacture 76, 49-60 (2014).

[4] E. Ezugwu, Z. Wang, and A. Machado, Journal of Materials Processing Technology 86, 1-16 (1999).

[5] D. Dudzinski and A. Molinari, International Journal of Mechanical Sciences 39, 369-389 (1997).

[6] Y. Ayed, G. Germain, A. Ammar, and B. Furet, Wear 305, 228-237 (2013).

[7] T. B. Bouchnak, "Etude du comportement en sollicitations extrłmes et de l'usinabilit d'un nouvel alliage de titane aronautique : le ti555-3," Ph.D. thesis, Ecole Nationale Suprieure d'Arts et Mtiers-ParisTech 2010.

[8] F. Pusavec, A. Deshpande, S. Yang, R. M’Saoubi, J. Kopac, O. W. Dillon, and I. Jawahir, Journal of Cleaner Production 81, 255- 269 (2014).

[9] D. Umbrello, F. Micari, and I. Jawahir, CIRP Annals 61, 103-106 (2012).

[10] Y. Ayed, G. Germain, M. Pubill, P. Kowalewski, and D. Locufier, The International Journal of Advanced Manufacturing Technology 93, 1199-1206 (2017).

[11] M. Dhananchezian and M. P. Kumar, Cryogenics 51, 34-40 (2011).

[12] Y. Kaynak, The International Journal of Advanced Manufacturing Technology 72, 919-933 (2014).

[13] N. Patil, A. Asem, R. Pawade, D. Thakur, and P. Brahmankar, Procedia CIRP 24, 86- 91 (2014).

[14] S. Cordes, F. Hbner, and T. Schaarschmidt, Procedia CIRP 14, 401- 405 (2014).

[15] B. D. Jerold and M. P. Kumar, Cryogenics 52, 569 - 574 (2012).

[16] A. Bagherzadeh and E. Budak, Tribology International 119, 510- 520 (2018). 